Bangladesh Journal of Neuroscience 2014; Vol. 30 (1) : 16-22

\title{
Asymptomatic Neuropathy in Recently Diagnosed Diabetic Patients: Electrophysiological Evaluation
}

\author{
ABU SALEH MD BADRUL HASAN ${ }^{1}$, BIPLOB KUMAR ROY², KAZI GIASUDDIN AHMED³, \\ MD RAFIQUL ISLAM ${ }^{4}$, AKM ANWAULLAH ${ }^{4}$, HASAN ZAHIDUR RAHMAN ${ }^{4}$, \\ QUAZI DEEN MOHAMMAD ${ }^{5}$, SK MAHBUB ALAM ${ }^{6}$
}

\begin{abstract}
:
Aim \& background: As significant electrophysiological changes are found in asymptomatic neuropathy in diabetes mellitus and electrophysiological studies of nerve conduction velocity are our most sensitive tools to quantify early abnormalities, therefore, we tried to find out status of asymptomatic peripheral nerve dysfunction in recently diagnosed diabetic patients in Bangladesh perspective. Method:This study was carried out at BSMMU and BIRDEM during November 2005 and April 2006. The study included 60 subjects, 30 recently diagnosed diabetic subjects (14 male, 16 female).
\end{abstract}

None had neuropathic symptoms or signs. All cases were selected randomly diagnosed by ADA criteria accepted by WHO. Thirty healthy controls with mean age comparable to that of diabetic subject were selected from the friends of the subjects and patients attending neurology outdoor of BSMMU. Result:Findings (mean $\pm S D$ ) were (case and control, respectively): Tibial nerve, DML 4.05 \pm 0.81 and $3.84 \pm 0.70 \mathrm{msec}(P>0.10)$, CMAP 16.90 \pm 5.14 and 19.49 $\pm 4.73 \mathrm{mV}(P<0.05), \mathrm{MCV} 45.43 \pm 4.55$ and $48.24 \pm 4.72 \mathrm{~m} /$ $s(P<0.05)$, and $F$ latency $45.09 \pm 12.43$ and $42.50 \pm 8.93 \mathrm{msec}(P>0.10)$; peroneal nerve, DML 4.12 \pm 1.10 and $4.03 \pm 0.67 \mathrm{msec}(P>0.50)$, CMAP $5.80 \pm 2.89$ and $6.97 \pm 1.79 \mathrm{mV}$ $(P>0.05), M C V \quad 43.10 \pm 8.89$ and $48.27 \pm 3.56 \mathrm{~m} / \mathrm{s}(P<0.01)$, and $F$ latency $50.27 \pm 10.81$ and 41.32 $\pm 3.05 \mathrm{msec}(P<0.001)$; median nerve, $D M L 3.57 \pm 0.46$ and $3.55 \pm 0.52 \mathrm{msec}$ $(P>0.50), C M A P 16.33 \pm 4.24$ and 17.84 $\pm 3.73 \mathrm{mV}(P>0.10)$ and MCV 55.16 \pm 5.33 and $57.70 \pm 4.33 \mathrm{~m} / \mathrm{s}(P<0.05)$, and $F$ latency $25.08 \pm 5.28$ and $24.39 \pm 4.83 \mathrm{msec}(P>0.50)$; and ulnar nerve DML 2.57 \pm 0.33 an $3.17 \pm 0.61 \mathrm{msec}(P<0.001), C M A P 14.65 \pm 3.32$ and $17.29 \pm 6.83 \mathrm{mV}(P>0.05), M C V 55.74 \pm 5.00$ and $58.50 \pm 5.13 \mathrm{~m} / \mathrm{s}(P<0.05), F$ latency $25.09 \pm 5.35$ and $25.82 \pm 3.33 \mathrm{msec}(P>0.50)$; sural nerve, $D S L 2.46 \pm 0.68$ and $3.12 \pm 0.45$ msec $(P<0.001)$, SNAP 19.44 \pm 10.25 and $25.32 \pm 7.88 \mathrm{iV}(P<0.05)$, SCV $49.95 \pm 10.22$ and 52.46 $\pm 3.96 \mathrm{~m} / \mathrm{s}(P>0.10)$; median nerve, DSL $2.52 \pm 0.39$ and $2.77 \pm 0.49 \mathrm{msec}$

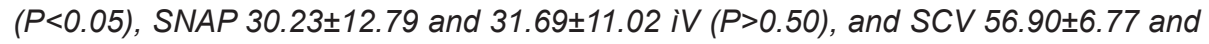
$57.41 \pm 5.85 \mathrm{~m} / \mathrm{s}(P>0.50)$; and ulnar nerve, DSL $2.03 \pm 0.39$ and $2.48 \pm 0.49 \mathrm{msec}$

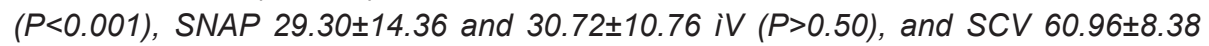
and $57.93 \pm 7.15 \mathrm{~m} / \mathrm{s}(P>0.10)$. Mean $( \pm S D) H b A_{1} c$ was significantly high $(P<0.001)$ in case group (7.10 $\pm 0.80 \%)$ compared to control $(5.51 \pm 0.65 \%)$. Mean $( \pm S D) S G P T$ showed no significant difference between case (36.10 $\pm 13.02 \mathrm{u} / \mathrm{L})$ and control $(36.20 \pm 7.94 \mathrm{u} / \mathrm{L})$. Similarly, mean $( \pm S D)$ total cholesterol also showed no significant difference between case $(201.57 \pm 37.56 \mathrm{mg} / \mathrm{dl})$ and control $(191.00 \pm 17.17 \mathrm{mg} / \mathrm{dl})$.

Conclusion: Motor nerve conduction parameters are affected more than sensory nerves and F-wave latencies are more frequently and early involved in these subjects. Abnormalities on nerve conduction was started in the feet rather than the hands. Clinical

1. Assistant Professor and head of Department of Neurology, Dinajpur Medical College and Hospital, Dinajpur

2. Associate Professor of neurology, Sylhet MAG Osmani Medical College \& Hospital, sylhet

3. Asst Professor of Neurology,National Institute of Neurosciences and Hospital, Dhaka

4. Professor. Department of Neurology, Bangabandhu Sheikh Mujib Medical University. BSMMU, Dhaka

5. Professor of Neurology \& Director, National Institute of Neurosciences and Hospital, Dhaka

6. Assistant Professor. Department of Neurology Bangabandhu Sheikh Mujib Medical University. BSMMU, Dhaka. 
spectrum of diabetic neuropathy is variable and may be asymptomatic, but once established as polyneuropathy, it is irreversible and may finally be disabling. Early detection of diabetic neuropathy is one of the major goals in the management of diabetes since timely intervention may substantially reduce mortality and morbidity.

Key words: Neuropathy, Diabetes, Electrophysiology

Abbreviation: MCV (motor nerve conduction velocity), DML (distal motor latency), CMAP (compound muscle action potential), SCV( sensory conduction velocity), SNC, $D S L$ (distal sensory latency), SNAP(sensory nerve action potential),

\section{Introduction:}

Diabetic neuropathy is defined as peripheral somatic or autonomic nerve damage attributable solely to diabetes mellitus ${ }^{1}$.It is not a single entity but a diverse group of disorders exhibiting a wide range of natural histories and clinical manifestations. ${ }^{1}$ Its manifestation ranges from subclinical alteration of nerve conduction, affecting practically all patients, who have diabetes for more than a few years, to extremely severe neuropathy with life threatening autonomic dysfunction².

This disorder is characterized by striking atrophy and loss of myelinated and unmyelinated fibres accompanied by Wallerian degeneration, segmental and paranodal demyelination and blunted nerve fibre regeneration. There is a significant relationship between clinical measures of neuropathic severity and myelinated nerve fibre loss. This progressive nerve fibre damage and loss parallels the degree and/or duration of hyperglycaemia ${ }^{3}$.

Microvascular abnormalities, particularly basement membrane thickening and endothelial cell hyperplasia are early features of diabetic microangiopathy and relate to neuropathic severity ${ }^{4}$. It has been suggested that microvascular disease plays a more important role in the development of neuropathy in type 2 than in type 1 diabetes $^{4}$. On the other hand, in type 1 diabetes, aetiology is metabolic rather than vascular ${ }^{3}$.

Patients with recently diagnosed or poorly controlled diabetes frequently show reduced nerve conduction velocity that improves rapidly with establishment of euglycaemia ${ }^{5}$. There is progressive deterioration of nerve function with time and duration of diabetes. ${ }^{6}$ Abnormal nerve function can be due to metabolic component, which can rapidly be reversed and is greatest in the early stages of neuropathy and a structural (more permanent) component occurring later in the disease process ${ }^{6}$.

As significant electrophysiological changes are found in asymptomatic neuropathy in diabetes mellitus and electrophysiological studies of nerve conduction velocity are our most sensitive tools to quantify early abnormalities, therefore, this study was designed to find out the real asymptomatic peripheral nerve dysfunction in recently diagnosed diabetic patients in Bangladesh perspective.

\section{Methods:}

This observational study was carried out in the Department of Neurology, Bangabandhu Sheikh Mujib Medical University (BSMMU), Dhaka, and Endocrinology Outpatient Department, Bangladesh Institute of Research and Rehabilitation in Diabetes, Endocrine and Metabolic Disorders (BIRDEM), Dhaka, during November 2005 and April 2006.

A total number of 60 patients were randomly selected for this study. Out of 60 subjects, 30 were recently diagnosed diabetics and 30 were control (non diabetics). Healthy controls with mean age comparable to that of diabetic subjects were selected from the friends of the subjects and patients attending neurology outdoor at BSMMU. All were age and sex matched. All the volunteers were apparently healthy as assessed by detailed medical history and clinical examination. None of them had history of diabetes up to second degree relations. None of the female control was pregnant. Thirty recently diagnosed diabetic subjects attending Endocrinology Outpatient Department, BIRDEM, were included consecutively. All recently diagnosed diabetic subjects had no neuropathic symptoms or signs. All cases were selected randomly by ADA criteria accepted by WHO. 
Inclusion criteria: Recently diagnosed diabetic subjects of either sex having no history of taking antidiabetic agent in the recent or remote past were included in this study. ADA criteria accepted by $\mathrm{WHO}$ were followed for the diagnosis of diabetes; age between 12 and 60 years.

Exclusion criteria: Presence of symptoms or signs of neuropathy; presence of other causes of neuropathy, such as CRF, alcohol, drugs and toxins, malignancy, etc.; presence of other comorbid conditions, such as stroke, PD, COPD, pregnancy, etc.; and presence of family history of neuropathy

Neurophysiological examinations: Were done by NCS of one upper and one lower limb to see motor and sural sensory nerve conduction parameters between case and control groups. For this purpose, median, ulnar, tibial, peroneal and sural nerves were investigated for underlying asymptomatic neuropathy.

Measurement of nerve conduction parameters: Nerve conduction velocity was measured by a standard EMG machine in a room with a temperature of $37^{\circ} \mathrm{C}$. Nerve conduction parameters were included according to the protocol recommended by San Antonio Conference on Diabetic Neuropathy. For upper limb, unilateral studies of motor and sensory conduction of ulnar nerve and median nerve, including F wave latencies were measured. For lower limbs, unilateral study of tibial and peroneal nerves for motor conduction including $\mathrm{F}$ wave latency were measured. Unilateral study of sural nerve for sensory conduction was done in lower limbs.
All measurements were performed with surface electrodes and measurements were recorded in a form used in the Department of Neurology, BSMMU. Nerves were stimulated using $1 \mathrm{~ms}$ electrical pulse at a repetition rate of 1 per second with intensity sufficient to elicit maximum amplitude of compound muscle action potential (CMAP) and sensory nerve action potential (SNAP).

Collected data were recorded on predesigned data collections sheet. Comparison between the groups was done by unpaired Student's ' $t$ ' test using computer based software, Statistical Package for Social Science (SPSS).

\section{Results:}

Table I shows characteristics of the study subjects. In case and control group, respectively, there were $13(43.3 \%)$ and $14(46.7 \%)$ male and $17(56.7 \%)$ and $16(53.3 \%)$ female. Mean $( \pm S D)$ age was $40.37 \pm 12.48$ years (case) and $40.37 \pm 12.48$ years (control). No significant variation was observed between sex and age. Mean $( \pm S D) \mathrm{HbA}_{1} \mathrm{c}$ was significantly high $(P<0.001)$ in case group $(7.10 \pm 0.80 \%)$ compared to control $(5.51 \pm 0.65 \%)$. Mean $( \pm S D)$ SGPT showed no significant difference between case $(36.10 \pm 13.02 \mathrm{u} / \mathrm{L})$ and control $(36.20 \pm 7.94 \mathrm{u} / \mathrm{L})$. Similarly, mean $( \pm S D)$ total cholesterol also showed no significant difference between case $(201.57 \pm 37.56 \mathrm{mg} / \mathrm{dl})$ and control (191.00 $\pm 17.17 \mathrm{mg} / \mathrm{dl})$.

Table Il shows comparison of motor nerve conduction parameters between case and control groups.

Table-I

Characteristics of the study subjects

\begin{tabular}{|c|c|c|c|c|c|}
\hline \multirow{2}{*}{$\begin{array}{l}\text { Parameters } \\
\text { Sex }\end{array}$} & \multicolumn{2}{|c|}{ Case $(n=30)$} & \multicolumn{2}{|c|}{ Control $(n=30)$} & \multirow{2}{*}{$\begin{array}{l}\text { P value } \\
>0.50^{\text {ns }}\end{array}$} \\
\hline & No. & $(\%)$ & No. & $(\%)$ & \\
\hline Male & 13 & (43.3) & 14 & (46.7) & \\
\hline Female & 17 & $(56.7)$ & 16 & (53.3) & \\
\hline Mean $\pm S D$ & \multicolumn{2}{|c|}{ Mean $\pm S D$} & & & \\
\hline Age (years) & \multicolumn{2}{|c|}{$40.37 \pm 12.48$} & \multicolumn{2}{|c|}{$40.37 \pm 12.48$} & $>0.50^{\mathrm{ns}}$ \\
\hline $\mathrm{HbA}_{1} \mathrm{c}(\%)$ & \multicolumn{2}{|c|}{$7.01 \pm 0.80$} & \multicolumn{2}{|c|}{$5.51 \pm 0.65$} & $<0.001^{* * *}$ \\
\hline SGPT (u/L) & \multicolumn{2}{|c|}{$36.10 \pm 13.02$} & \multicolumn{2}{|c|}{$36.20 \pm 7.94$} & $>0.50^{\mathrm{ns}}$ \\
\hline $\begin{array}{l}\text { Total cholesterol } \\
(\mathrm{mg} / \mathrm{dl})\end{array}$ & & 56 & \multicolumn{2}{|c|}{$191.00 \pm 17.17$} & $>0.10^{\mathrm{ns}}$ \\
\hline
\end{tabular}

Chi square test/Unpaired Student's ' $t$ ' test ns $=$ Not significant, ${ }^{* * *}=$ Significant 
Tibial nerve: Mean $( \pm S D)$ DML $(4.05 \pm 0.81$ and $3.84 \pm 0.70 \mathrm{msec})$ and $F$ latency $(45.09 \pm 12.43$ and $42.50 \pm 8.93 \mathrm{msec}$ ) showed no significant difference between case and control. Mean $( \pm S D)$ CMAP $(16.90 \pm 5.14$ and $19.49 \pm 4.73 \mathrm{msec})$ and $\mathrm{MCV}$ $(45.43 \pm 4.55$ and $48.24 \pm 4.72 \mathrm{~m} / \mathrm{s}$ ) were significantly $(P<0.05)$ low in case group.

Peroneal nerve: Mean $( \pm S D)$ DML $(4.12 \pm 1.10$ and $4.03 \pm 0.67 \mathrm{msec})$ and CMAP $(5.80 \pm 2.89$ and $6.97 \pm 1.79 \mathrm{mV}$ ) showed no significant difference between groups. Mean $( \pm S D)$ MCV was significantly low $(P<0.01)$ in case group $(43.10 \pm 8.89$ $\mathrm{m} / \mathrm{s})$ compared to control $(48.27 \pm 3.56 \mathrm{~m} / \mathrm{s})$. However, mean $( \pm S D) F$ latency was significantly high $(\mathrm{P}<0.001)$ in case $(50.27 \pm 10.81 \mathrm{msec})$ compared to control $(41.32 \pm 3.05 \mathrm{msec})$.

Median nerve: Mean $( \pm S D)$ DML $(3.57 \pm 0.46$ and $3.55 \pm 0.52 \mathrm{msec})$, CMAP $(16.33 \pm 4.24$ and $17.84 \pm 3.73 \mathrm{mV})$ and $F$ latency $(25.08 \pm 5.28$ and
$24.39 \pm 4.83 \mathrm{msec}$ ) showed no significant difference between case and control groups. However, mean $( \pm S D) M C V$ was significantly low $(P<0.05)$ in case group $(55.16 \pm 5.33 \mathrm{~m} / \mathrm{s})$ compared to control group $(57.70 \pm 4.33 \mathrm{~m} / \mathrm{s})$.

Ulnar nerve: Mean $( \pm S D)$ CMAP $(14.65 \pm 3.32$ and $17.29 \pm 6.83 \mathrm{mV})$ and $F$ latency $(25.09 \pm 5.35$ and $25.82 \pm 3.33 \mathrm{msec}$ ) showed no significant difference between case and control groups. Mean $( \pm S D) D M L$ was significantly low $(P<0.001)$ in case group $(2.57 \pm 0.33 \mathrm{msec})$ compared to control group (3.17 $\pm 0.61 \mathrm{msec})$. Similarly, Mean $( \pm S D)$ MCV was also significantly low $(P<0.05)$ in case group $(55.74 \pm 5.00 \mathrm{~m} / \mathrm{s})$ compared to control group $(58.50 \pm 5.13 \mathrm{~m} / \mathrm{s})$.

Table III shows comparison of sensory nerve conduction parameters between case and control groups.

Table-II

Comparison of motor nerve conduction parameters

\begin{tabular}{|c|c|c|c|}
\hline Parameters & $\begin{array}{c}\text { Case }(n=30) \\
(\text { Mean } \pm S D)\end{array}$ & $\begin{array}{c}\text { Control }(n=30) \\
(\text { Mean } \pm S D)\end{array}$ & $P$ value \\
\hline \multicolumn{4}{|l|}{ Tibial nerve } \\
\hline DML (msec) & $4.05 \pm 0.81$ & $3.84 \pm 0.70$ & $>0.10^{\mathrm{ns}}$ \\
\hline CMAP (mV) & $16.90 \pm 5.14$ & $19.49 \pm 4.73$ & $<0.05^{*}$ \\
\hline $\operatorname{MCV}(\mathrm{m} / \mathrm{s})$ & $45.43 \pm 4.55$ & $48.24 \pm 4.72$ & $<0.05^{*}$ \\
\hline F latency (msec) & $45.09 \pm 12.43$ & $42.50 \pm 8.93$ & $>0.10^{\text {ns }}$ \\
\hline \multicolumn{4}{|l|}{ Peroneal nerve } \\
\hline DML (msec) & $4.12 \pm 1.10$ & $4.03 \pm 0.67$ & $>0.50^{\mathrm{ns}}$ \\
\hline CMAP (mV) & $5.80 \pm 2.89$ & $6.97 \pm 1.79$ & $>0.05^{\mathrm{ns}}$ \\
\hline $\operatorname{MCV}(\mathrm{m} / \mathrm{s})$ & $43.10 \pm 8.89$ & $48.27 \pm 3.56$ & $<0.01^{* *}$ \\
\hline F latency (msec) & $50.27 \pm 10.81$ & $41.32 \pm 3.05$ & $<0.001^{* * *}$ \\
\hline \multicolumn{4}{|l|}{ Median nerve } \\
\hline DML (msec) & $3.57 \pm 0.46$ & $3.55 \pm 0.52$ & $>0.50^{\mathrm{ns}}$ \\
\hline CMAP (mV) & $16.33 \pm 4.24$ & $17.84 \pm 3.73$ & $>0.10^{\text {ns }}$ \\
\hline $\operatorname{MCV}(\mathrm{m} / \mathrm{s})$ & $55.16 \pm 5.33$ & $57.70 \pm 4.33$ & $<0.05^{*}$ \\
\hline F latency (msec) & $25.08 \pm 5.28$ & $24.39 \pm 4.83$ & $>0.50^{\text {ns }}$ \\
\hline \multicolumn{4}{|l|}{ Ulnar nerve } \\
\hline DML (msec) & $2.57 \pm 0.33$ & $3.17 \pm 0.61$ & $<0.001^{\star * *}$ \\
\hline CMAP (mV) & $14.65 \pm 3.32$ & $17.29 \pm 6.83$ & $>0.05^{\mathrm{ns}}$ \\
\hline $\operatorname{MCV}(\mathrm{m} / \mathrm{s})$ & $55.74 \pm 5.00$ & $58.50 \pm 5.13$ & $<0.05^{*}$ \\
\hline F latency (msec) & $25.09 \pm 5.35$ & $25.82 \pm 3.33$ & $>0.50^{\text {ns }}$ \\
\hline
\end{tabular}

Unpaired Student's ' $\mathrm{t}$ ' test

ns $=$ Not significant, ${ }^{* / * * / * *}=$ Significant 
Table-III

Comparison of sensory nerve conduction parameters

\begin{tabular}{lccc}
\hline Parameters & $\begin{array}{c}\text { Case }(\mathrm{n}=30) \\
(\text { Mean } \pm S D)\end{array}$ & $\begin{array}{c}\text { Control }(\mathrm{n}=30) \\
(\text { Mean } \pm S D)\end{array}$ & P value \\
\hline Sural nerve & & & \\
DSL $(\mathrm{msec})$ & $2.46 \pm 0.68$ & $3.12 \pm 0.45$ & $<0.001^{* * *}$ \\
SNAP $(\mathrm{iV})$ & $19.44 \pm 10.25$ & $25.32 \pm 7.88$ & $<0.05^{*}$ \\
SCV $(\mathrm{m} / \mathrm{s})$ & $49.95 \pm 10.22$ & $52.46 \pm 3.96$ & $>0.10^{\text {ns }}$ \\
Median nerve & & & \\
DSL $(\mathrm{msec})$ & $2.52 \pm 0.39$ & $2.77 \pm 0.49$ & $<0.05^{*}$ \\
SNAP $(\mathrm{iV})$ & $30.23 \pm 12.79$ & $31.69 \pm 11.02$ & $>0.50^{\text {ns }}$ \\
SCV $(\mathrm{m} / \mathrm{s})$ & $56.90 \pm 6.77$ & $57.41 \pm 5.85$ & $>0.50^{\text {ns }}$ \\
Ulnar nerve & & & \\
DSL $(\mathrm{msec})$ & $2.03 \pm 0.39$ & $2.48 \pm 0.49$ & $<0.001^{* * *}$ \\
SNAP $(\mathrm{iV})$ & $29.30 \pm 14.36$ & $30.72 \pm 10.76$ & $>0.50^{\text {ns }}$ \\
SCV $(\mathrm{m} / \mathrm{s})$ & $60.96 \pm 8.38$ & $57.93 \pm 7.15$ & $>0.10^{\text {ns }}$ \\
\hline
\end{tabular}

Unpaired Student's 't' test

ns $=$ Not significant, ${ }^{*}{ }^{* * *}=$ Significant

Sural nerve: Mean $( \pm S D)$ SCV showed no significant difference between case $(49.95 \pm 10.22 \mathrm{~m} / \mathrm{s})$ and control $(52.46 \pm 3.96 \mathrm{~m} / \mathrm{s})$ groups. Mean $( \pm S D) \mathrm{DSL}$ $(2.46 \pm 0.68$ and $3.12 \pm 0.45 \mathrm{msec})$ was significantly low $(P<0.001)$ in case group compared to control. Also mean $( \pm S D)$ SNAP $(19.44 \pm 10.25$ and $25.32 \pm 7.88 \mathrm{iV})$ was significantly low $(P<0.05)$ in case group.

Median nerve: Mean $( \pm S D)$ SNAP $(30.23 \pm 12.79$ and $31.69 \pm 11.02 \mathrm{iV})$ and SCV (56.90 \pm 6.77 and $57.41 \pm 5.85 \mathrm{~m} / \mathrm{s}$ ) showed no significant difference between case and control groups. However, mean $( \pm S D)$ DSL $(2.52 \pm 0.39$ and $2.77 \pm 0.49 \mathrm{msec})$ was significantly low $(P<0.05)$ in case group.

Ulnar nerve: Mean $( \pm S D)$ SNAP $(29.30 \pm 14.36$ and $30.72 \pm 10.76 \mathrm{iV})$ and SCV $(60.96 \pm 8.38$ and $57.93 \pm 7.15 \mathrm{~m} / \mathrm{s}$ ) showed no significant difference between groups. However, mean $( \pm S D)$ DSL $(2.03 \pm 0.39$ and $2.48 \pm 0.49 \mathrm{msec})$ was significantly low $(\mathrm{P}<0.001)$ in case group compared to control.

\section{Discussion:}

The present study was undertaken to evaluate the asymptomatic neuropathy in recently diagnosed, untreated diabetic subjects of Bangladesh by electrodiagnosis and to explore whether abnormal $\mathrm{HbA}_{1} \mathrm{C}$ value, SGPT value and total cholesterol value relate to peripheral nerve dysfunction in diabetic patients.

The healthy controls and diabetic subjects were of comparable age and sex. Among the diabetic subjects, female predominated $(56.7 \%)$ over males $(43.3 \%)$ (Table I). Like the other previous studies, these subjects were severely hyperglycemic. This high glycaemic state can be explained by the fact that these patients were recently diagnosed and did not get any treatment. Moreover, one of the characteristic finding of these diabetic subjects in this region is moderate to severe hyperglycaemia ${ }^{7}$.

Serum $\mathrm{HbA}_{1} \mathrm{C}(\%)$ level was statistically significantly higher $(P<0.001)$ in cases $(7.01 \pm 0.80 \%)$ compared to control $(5.51 \pm 0.65 \%)$ subjects (Table I). This high level of serum $\mathrm{HbA}_{1} \mathrm{C}(\%)$ was frequently found in other previous studies. One finding in MIT (multiple insulin injection therapy) treated patients with mean diabetes duration of 8.2 years indicates that very low mean $\mathrm{HbA}_{1} \mathrm{C}$ values (about $6 \%$ ) are required to prevent nerve dysfunction. On the other hand, mean $\mathrm{HbA}_{1} \mathrm{C}$ values over $9 \%$ invariably related to nerve dysfunction ${ }^{8}$. In electrophysiological investigation of diabetic patients, slowing of motor nerve conduction velocity has been found to be inversely correlated with the concentrations of $\mathrm{HbA}_{1} \mathrm{C}$. It has 
been demonstrated that the control of blood glucose level protects against the development of neuropathy in type I diabetes. ${ }^{9}$ In one study, somatic large motor fiber abnormalities of lower extremities correlated with only $\mathrm{HbA}_{1} \mathrm{C}$ concentration, which confirmed the assumption that hyperglycemia is an essential factor in the involvement of long nerves. However, the motor and sensory nerve conduction abnormalities of upper extremity were not found to be correlating with $\mathrm{HbA}_{1} \mathrm{C}$ concentration, age and diabetes duration? .

We did not find any information regarding correlation between asymptomatic neuropathy and serum SGPT and serum total cholesterol in previous studies. We undertook these two variables (SGPT and total cholesterol) only for academic interest.

DML values of tibial nerve were slightly higher in diabetic subjects than control subjects but statistically not significant $(P>0.10)$. CMAP values of tibial nerve were statistically significantly lower in diabetic subjects than control subjects $(P<0.05)$. MCV values of tibial nerve were statistically significantly lower in diabetic subjects than control subjects $(P<0.05)$. $F$ latency values of tibial nerve were slightly higher in diabetic subjects than control subjects but statistically not significant $(P>0.10)$ (Table II).

DML values of peroneal nerve were slightly higher in diabetic subjects than control subjects but statistically not significant $(P>0.50)$. CMAP values were lower in diabetic subjects than control subjects but statistically not significant $(P>0.05)$. MCV values were statistically significantly lower $(P<0.10)$ in diabetic subjects than control subjects. F latency values were statistically significantly higher $(P<0.001)$ in diabetic subjects than control subjects (Table II).

DML values of median nerve did not show statistically any significant difference $(P>0.50)$. CMAP values were slight lower in diabetic subjects than control subjects but statistically not significant $(P>0.10)$. MCV values were statistically significantly lower $(P<0.05)$ in diabetic subjects than control subjects. $F$ latency values showed statistically no significant difference $(P>0.50)$. DSL values were slightly lower in diabetic subjects than control subjects. Those were statistically significant $(P<0.05)$. SNAP and $S C V$ values were slightly lower in diabetic subjects but statistically not significant $(P>0.50)$ (Table II).

DML values of ulnar nerve were slightly lower in diabetic subjects but statistically significant $(P<0.001)$. CMAP values were lower in diabetic subjects but statistically not significant $(P>0.05)$. $\mathrm{MCV}$ values were statistically significantly lower $(P<0.05)$ in diabetic subjects. $F$ latency values showed statistically no significant difference $(P>0.50)$. DSL values of ulnar nerve were slightly lower in diabetic subjects but statistically significant $(P<0.001)$. SNAP values were slightly lower but statistically not significant $(P>0.50)$. SCV values were slightly higher in diabetics but statistically not significant $(P>0.10)$ (Table II).

DSL values of sural nerve were slightly lower in diabetic subjects but statistically significant $(P<0.001)$. SNAP values were statistically significantly lower $(P<0.05)$ in diabetic subjects. SCV values were lower in diabetic subjects but statistically not significant $(P>0.10)$ (Table III).

Most of the nerve conduction parameters tended to differ statistically significantly in diabetic subjects from those of control subjects. Same dysfunction of peripheral nerves were reported previously in recently detected diabetic subjects ${ }^{10}$. Our findings provide supportive evidence for the existence of an acute metabolic component of diabetic neuropathy. ${ }^{10}$ Findings of abnormalities of motor nerve function parameters support the hypothesis that abnormalities of motor nerve conduction velocities are related to their level of hyperglycemia in young diabetic subjects ${ }^{11}$.

Some investigators suggested that sural nerve dysfunction is the most common indicator of peripheral nerve dysfunction, and it is the first to be affected, and correlates most closely with the neuropathological findings ${ }^{9}$.

In previous study, correlation found between high serum $\mathrm{HbA}_{1} \mathrm{C}$ level and asymptomatic nerve dysfunction ${ }^{8}$. Correlation did not found clearly between high serum SGPT, high total serum cholesterol and asymptomatic nerve dysfunction. These two variables (SGPT and total cholesterol) were taken into consideration only for academic 
interest to find out relationship with asymptomatic neuropathy.

After evaluating the results, we suggest that the most useful and practical nerves for the electrophysiological study in diabetic patients are the motor and sensory nerves of lower extremity. The prominence of motor, sensory and autonomous nerve dysfunction in lower extremity must be correlated with the length of these nerves. All the necessary proteins which are synthesized in cell body are transmitted to distal parts of the nerves by axoplasmic flow and maintain the anatomic and functional integrity of the nerve. The interruption of axoplasmic flow in long nerves is more prominent than in short nerves. One data indicate that in early period, the axoplasmic flow might have been affected 10

\section{Conclusion:}

Clinical spectrum of diabetic neuropathy is variable. It may be asymptomatic but once established as polyneuropathy, it is irreversible and may finally be disabling. Early detection of diabetic neuropathy is one of the major goals in the management of diabetes since timely intervention may substantially reduce mortality and morbidity. Metabolic peculiarities of young diabetics of Bangladesh have given the opportunity to see the influence of hyperglycemia on functional status of peripheral nerves in these subjects. To evaluate functional status of peripheral nerves, nerve conduction parameters and $F$ wave latencies need to be studied. Motor nerve conduction parameters are affected more than sensory nerves and $\mathrm{F}$-wave latencies are more frequently and early involved in these subjects.

\section{References:}

1. ADA [American Diabetic Association]. Consensus statement: standardized measures in diabetic neuropathy. Diabetic Care, vol. 18, suppl. 1.

2. Said G, Goulean G, Salma G, Tchobroutsky G. Severe early onset polyneuropathy in insulin dependent diabetes mellitus: a clinical pathological study. N Engl J Med.1992; 326(19):1251 63.

3. Douglas AG, Sima AAF, Stevens MJ, Feldman EL, Lattimar SA. Complications: neuropathy, pathologic considerations. Diabetes Care. 1992;15 (12):1902 25.

4. Malik RA.The pathology of human diabetic neuropathy. Diabetes. 1997; 46(2).S50 S53.

5. Gregerson G. Variations in motor conduction velocity produced by acute changes of the metabolic state in diabetic patients. Diabetologia. 1968; 4:273 77.

6. Pfeifer MA, Schumer MP. Perspectives in diabetes, clinical trials of diabetic neuropathy: past, present and future. Diabetes.1995; 44: 1355-61

7. Bajaj JS. Malnutrition related ketosis resistant diabetes mellitus: classification, causes and mechanism. In: Krall LP, editor. World book of diabetes in practice. Amsterdam: Elsevier, 1986; 27680.

8. Hyllienwark L, Brismar T, Ludvigsson J. Subclinical nerve dysfunction in children and adolescents with IDDM. Diabetologia. 1995; 38:.685 92.

9. Karsidag S, Morali S, Sargin M, Salman S, Karsidag K, Us O. 2005. The electrophysiological findings of subclinical neuropathy in patients with recently diagnosed type 1 diabetes mellitus. Diabet Res Clin Pract.2005;67:211 19.

10. Fraser DM, Campbell IW, Ewing DJ, Murray A, Neilson JM, Clarke BF. 1977. Peripheral and autonomic nerve function in newly diagnosed diabetes mellitus. Diabetes. 1977; 26:546 50.

11. Graff RJ, Jeffery B, Heller E, Pote D. Nerve conduction abnormalities in untreated maturity onset diabetes: relation to levels of fasting plasma glucose and glycosylated haemoglobin. Ann Intern Med.1979;.298 303. 